\title{
Simone Weil y la libertad por medio del trabajo
}

\author{
DAVID SOLÍS NOVA* \\ Universidad Católica de la Santísima Concepción (Chile) \\ dsolis@ucsc.cl
}

\begin{abstract}
Resumen
En este artículo queremos desarrollar las nociones que Simone Weil tiene del trabajo humano a lo largo de su obra. Comenzaremos con una revisión de sus primeros escritos políticos y sociales sobre la condición obrera y luego ahondaremos en sus obras influenciadas por la experiencia cristiana. Revisaremos su permanente deseo de poder conjugar el trabajo manual con el trabajo intelectual y las negativas consecuencias que ella ve en su separación, además de su análisis de la condición obrera antes y después de su experiencia de trabajo en las fábricas. Finalmente, intentaremos responder cuál es la postura metafísica y antropológica que reside tras esta propuesta weiliana y las posibilidades de proponer en propiedad la tesis de la filósofa francesa como una noción cristiana del trabajo. Concluiremos resaltando lo que, a nuestro modo de ver, son los principales aportes de la filósofa a una doctrina del trabajo liberador para la condición humana.
\end{abstract}

Palabras claves: Simone Weil, trabajo, descreación, condición obrera, cristianismo.

\section{Simone $W$ eil and freedom through work}

\begin{abstract}
In this article we want to develop the notions that Simone Weil has of human labor throughout his work. We begin with a review of his early political and social writings on the working condition and then delve into his works influenced by the Christian experience. We will review her permanent desire to be able to combine manual labor with intellectual work and the negative consequences she sees in her separation, as well as her analysis of the working class before and after her experience of working in factories. Finally, we will try to answer what is the metaphysical and anthropological posture that resides behind this weilian proposal and the possibilities of proposing in property the thesis of the french philosopher as a Christian notion of the work. We will conclude by highlighting what, in our view, are the main contributions of the philosopher to a doctrine of liberating work for the human condition.
\end{abstract}

Key words: Simone Weil, work, decreation, working condition, Christianity.

\footnotetext{
* Doctor en Filosofía por la Universidad Pontificia de Salamanca. Académico de la carrera de Licenciatura en Filosofía, Universidad Católica de la Santísima Concepción, Chile. Profesor de Antropología filosófica y ética. Entre sus artículos: "El milagro de San Francisco: la lectura de Max Scheler a la vida del santo de Asís" (2011), "La definición del amor en la filosofía de Max Scheler" (2011), y "El resentimiento y la moral: una clarificación desde la filosofía de Max Scheler” (2012).
} 
INTRODUCCIÓN

El objetivo de este artículo es indagar en torno a la noción y sentido del trabajo humano en la obra de Simone Weil. A través de una metodología de revisión bibliográfica-documental trataremos de llegar a conclusiones acerca de la importancia de la concepción del trabajo a lo largo de la obra de la filósofa y cómo en esta concepción se manifiestan los pilares antropológicos y metafísicos de todo su pensamiento. Junto con ello, pretendemos, a la luz de estos resultados, verificar la posibilidad de que esta propuesta pueda ser considerada como una invitación para renovar el entendimiento del rol del trabajo en la amplitud de la experiencia cristiana, tal como lo deseaba la misma pensadora. Weil ha extendido su prestigio principalmente por sus pensamientos religiosos posteriores a sus experiencias místicas, pero creemos que es bueno también volver a sus obras primeras y sus preocupaciones iniciales para entender muchos de aquellos tópicos que han permanecido inalterables a lo largo de su trayectoria filosófica. Sin embargo, la lectura de estas obras primeras nos pueden mostrar también una diferencia o un segundo impulso en el desarrollo de su filosofía. Esto último tiene que ver directamente con nuestra hipótesis que va en la dirección de señalar que la noción weiliana del trabajo es tan crucial en su filosofía que el cambio que puede percibirse en esta concepción a lo largo de su obra obedece a un cambio importante en su cosmovisión, sobre todo en los escritos posteriores a su encuentro con el cristianismo. Plantearemos el problema de si se puede hablar en Weil, al mismo tiempo, de una propuesta cristiana del trabajo en base a estos antecedentes, sobre todo considerando las riquezas que podría otorgar una propuesta como esta (Juan Pablo II: 1981, n.3). Finalmente, quisiéramos mostrar los puntos que, a nuestro parecer, son los más importantes a tener en cuenta en las posturas en torno al trabajo humano de la filósofa francesa.

\section{SIMONE WEIL Y LA CRÍTICA A LA FUNCIÓN}

La cuestión del sentido del trabajo es posible encontrarla desde los primeros escritos de Simone Weil. Las primeras obras e intereses de la pensadora están inclinados principalmente al análisis del trabajo del proletariado y sus repercusiones en la estructura de la sociedad capitalista. Son trabajos que se encuentran en la órbita de Proudhon y Marx, pero que siempre manifiestan la libertad de espíritu y el amplio bagaje filosófico y literario que caracterizó a Weil. Fueron publicadas principalmente en revistas dedicadas al estudio de la situación de los trabajadores y que podemos fechar aproximadamente entre 1927 y 1937. Recordemos tam- 
bién que su deseo de conocer la condición proletaria en toda su verdad la llevó a hacerse obrera de distintas fábricas desde diciembre de 1934 hasta agosto de 1935. Sus análisis sobre estas cuestiones están inevitablemente traspasados de esta experiencia y nunca dejaron de preocupar a la filósofa, manteniéndose firmes, pero renovados, en los tiempos posteriores a su encuentro con el cristianismo.

En estas obras en torno a la opresión y la situación obrera la crítica a la función ocupa un lugar central, ya que encuentra en ella la raíz de la burocratización del trabajo de su época tanto en su versión capitalista como marxista. Weil ya está muy informada de la situación en Rusia y considera que la condición de los trabajadores no ha cambiado sustancialmente después de la revolución de octubre de 1917. Es posible que el rostro y el discurso del opresor haya cambiado pero la opresión se mantiene. Ella explica estas afirmaciones a partir de lo que llama la opresión por medio de la función. Efectivamente, si bien ya no se puede identificar al opresor con el dueño de los medios de producción como en la tradicional tesis marxista en torno al capitalismo, la opresión la ejerce ahora el orden burocrático que esconde su carácter elitista en la organización de distintas funciones. El opresor ahora es esta función que Weil entiende como una labor hiper-dividida y especializada que le impide al trabajador conocer los fines y consecuencias de su trabajo. Estos fines son conocidos sólo por los directivos, es decir, por los que poseen el monopolio del pensamiento y las ideas. Weil critica fuertemente a Marx el que no haya podido ver que con su sistema quitaba la opresión a unos, pero se las entregaba a otros, en este caso, a una casta de burócratas, distintos al antiguo patrón, pero con el mismo objetivo de ocultar al trabajador el sentido y la ciencia de su trabajo.

Siempre le pareció una mala broma de Trosky — con quien pudo conversar detenidamente en París en 1933- el que todavía considerara que la URSS era un 'estado obrero'. Con algo de tristeza Weil comprueba que generalmente las revoluciones entregan el poder a los que ya lo tienen, es decir, generalmente triunfan en las revoluciones aquellos sectores sociales que, desde hace tiempo, aunque embozadamente, ya detentan las funciones directivas. Para reafirmar esto entrega los ejemplos de las 'hordas' bárbaras que ya se paseaban por el Imperio romano desde hace mucho tiempo y los burgueses de la Revolución francesa que ya conocían muy bien los palacios de la aristocracia: "Este género de acontecimientos llega a abolir los privilegios que no corresponden a ninguna función efectiva, pero no conmueve el reparto de los poderes y funciones que le están unidos" (Weil, 1955: 130). En el caso de Rusia, Weil piensa en una casta de burócratas, la policía y funcionarios del ejército que ya ejercían el poder desde la época de los zares. De hecho, la filósofa acerca 
sin ningún temor el estalinismo con el nacionalsocialismo de Alemania en la medida en que son estados burocráticos que oprimen a sus ciudadanos en nombre de la función hiper-dividida y carente de pensamiento que deben cumplir en el rol que el estado les ha impuesto. En 1933 señala: "El Partido Comunista Ruso no ha hecho más que reforzar el poder del Estado a expensas de la clase obrera" (Weil, 2007: 74).

El gran error que ve Weil en la doctrina marxista es haber puesto el acento en los poseedores de los medios de producción más que en la eliminación de toda opresión. No era tan difícil llegar a darse cuenta de que una dictadura del proletariado iba a necesitar de una casta dirigente que tomara las decisiones y una gran masa de hombres que obedeciera. De este escenario a una nueva situación de opresión hay un camino muy corto. Pese a todas las líneas dedicadas al trabajo en la obra de Marx, este no logró desentrañar la penosa situación y las causas bajo las que crujía y sangraba el trabajo de la era industrial. La filósofa lo ve clarísimo en el movimiento obrero francés donde cree que todavía el acento está puesto en resolver la cuestión de si los dueños de las fábricas deben entregar sus propiedades a los trabajadores: "Si mañana nos apoderamos de las fábricas, no sabríamos qué hacer con ellas y nos veríamos forzados a organizarlas tal como lo están actualmente, después de un tiempo de vacilación más o menos largo" (Weil, 1951a: 185). En el mismo sentido, se podría trabajar mañana en una fábrica de propiedad colectiva estando en la misma situación de opresión que siempre.

La gran causa de este trabajo alienado no es sólo que el obrero no reciba el producto de su trabajo, sino, sobre todo, que no puede y no se le permite comprender las finalidades y el sentido interno de su esfuerzo diario. Weil descubre el origen de toda alienación y disociación entre el trabajador y su obra en la ausencia de contemplación y atención dentro del mismo trabajo manual. La gran herida por la cual siguen sufriendo los trabajadores, incluso ya instalado el comunismo, es la separación entre trabajo manual y trabajo intelectual. En Weil esta separación alcanza las dimensiones de tragedia silenciosa y artera crueldad. En efecto, dividir hasta lo impensable el trabajo, en pequeñas y escuetas funciones, logra que el operario se especialice hasta el punto de no saber qué está haciendo ni mucho menos saber para quién o, lo que es aún peor, para qué está trabajando. Obreros dedicados más de 10 horas al día a ensamblar una pieza sin conocer su utilidad, sin ni siquiera saber cómo y por qué funciona ni mucho menos quiénes la usarán y qué beneficios humanos les podrá traer a estos usuarios. A los obreros se les esconden los aspectos técnicos, científicos, políticos, sociales, morales, económicos, filosóficos y culturales de su trabajo. No está pensando Weil en llenar de información inútil a los trabajadores, está pensando simplemente en que el traba- 
jador no puede sentirse efectivamente dueño de su trabajo si no conoce la inteligencia y el sentido que traspasa el objeto de su esfuerzo y dedicación diaria. En sus escritos sobre la experiencia en la fábrica señala:

La ignorancia total de aquello en lo que trabajamos es excesivamente desmoralizante. No se tiene la sensación de que un producto resulte de los esfuerzos que ha costado. No se siente uno en absoluto entre sus autores. Tampoco se ve ninguna relación entre el trabajo y el salario. La actividad parece arbitrariamente impuesta y arbitrariamente retribuida. Se tiene la sensación de ser un poco como los niños a quienes la madre, para tenerlos tranquilos, les da cuentas de collar para que las ensarten prometiéndoles caramelos (Weil, 1951a: 101).

Todas las piezas que se fabrican tienen su historia, pero el trabajador no tiene idea de esa historia ni cree que ha podido dejar alguna huella en ese producto, es decir, el trabajador no tiene la claridad de qué es lo que está aportando al mundo a través de su esfuerzo diario y perfectamente puede llegar a tener la impresión de que se ha cansado, se cansa y se seguirá cansando en vano.

La filósofa sostiene que, tanto en el capitalismo como en el comunismo de la URSS, esta comprensión de la interna inteligencia del trabajo se le ha entregado a los técnicos, a quienes, por otro lado, se les ha quitado el trabajo manual. Sólo los técnicos entienden qué es lo que se está haciendo y cuál es su sentido y sus consecuencias en todos los aspectos de la vida humana. Sin embargo, estos técnicos no tienen relación con los objetos producidos. Además, los obreros tienen relación con una sola función específica para producir ese objeto, pero carecen de toda la información que rodea al objeto que están ayudando a producir.

Esto se ejemplifica con toda claridad cuando describe la función de las máquinas en el trabajo de las fábricas como una especie de inteligencia cristalizada'. Efectivamente, pareciera que toda la ciencia, la técnica y el ingenio de la época se solidificaran, se materializaran en una máquina, una especie de inteligencia concreta que reduce a los trabajadores a ser simples subordinados o herramientas para ejecutar la acción. Pero la inteligencia ya no está en los trabajadores -que sólo ejecutan en función de ella un movimiento mecánico- sino en la misteriosa constitución de una máquina que encierra una ciencia oculta entre sus cables y aceros. La inteligencia se confía a la máquina, el movimiento autómata se confía al hombre. "En la manufactura y el artesanado, el trabajador se sirve de la herramienta; en la fábrica, sirve a la máquina" (Marx, 2009: 515). Recoge en su diario de la fábrica una expresión de una compañera de trabajo: "Nos toman por máquinas, otros están ahí para pensar por nosotras" 
(Weil, 1951a: 68). Por ello mismo Weil aboga por una ciencia que coopere en la liberación del trabajador, es decir, que cambie su dirección actual: una ciencia que piense una técnica que no reduzca al hombre a un engranaje más o menos intercambiable. Se puede concebir una ciencia cuyo fin último fuera el perfeccionamiento de la técnica no necesariamente para hacerla más poderosa, sino simplemente más consciente y más metódica. La filósofa tiene la clara convicción de que junto con el gran dominio que la ciencia ha logrado de la naturaleza, se ha logrado una gran capacidad de dominio social. Por una especie de fatal equilibrio la libertad que nos entregó la ciencia frente a la naturaleza la hemos perdido por la gran capacidad que hoy se tiene, gracias a la misma ciencia, de dominar y manipular a la población. Señala con toda tranquilidad Weil que incluso nuestro nivel de opresión por el sistema social es mayor que la opresión que ejercía la naturaleza en pueblos primitivos. Por ello propone una reformulación total de los objetivos de la ciencia (Sparling, 2012: 92; Bea, 1992: 70), de otro modo pasaremos siempre de una opresión a otra:

Así, a despecho del progreso, el hombre no ha salido de la condición servil en que se encontraba cuando, débil y desnudo, estaba librado a todas las fuerzas ciegas que componen el universo; simplemente el poder que lo mantiene de rodillas ha sido como transferido de la materia inerte a la sociedad que forma con sus semejantes (Weil, 1955: 77).

Para la filósofa hay que proponer una distinción entre dos revoluciones industriales, diferenciándose de otro tipo de teorizaciones al mismo respecto: una primera gran revolución industrial que de sobremanera ha significado un dominio notorio del hombre sobre muchas fuerzas de la naturaleza. Sin embargo, habría que distinguir una segunda etapa de esta revolución industrial en la que este dominio sobre la naturaleza se ha aplicado a la humanidad. Las fuerzas adquiridas por la técnica y el maquinismo son aplicadas ahora para manipular y subyugar a la población (Weil, 1951a: 182).

Por ello puede llegar a afirmar tajantemente que ni siquiera se puede soñar en una revolución mientras se mantenga el industrialismo. Las fuerzas creadas por el industrialismo son tan grandes que es casi imposible resistir a la tentación de no usarlas para aumentar el poder que detentamos sobre otras personas. En este sentido esboza una idea que se mantiene constante en su obra: el que tiene el poder no puede sino usarlo, el que tiene poder no puede sino seguir usufructuando de él. Alguien que teniendo el poder no lo utilizara, realizaría una acción antinatural. Más tarde, ya bajo la influencia del cristianismo, dirá más bien que sí se puede, 
pero no por una actitud antinatural, sino por intervención de lo sobrenatural.

Un capítulo aparte en esta discusión son las doctrinas de Taylor que aceleraron y perfeccionaron esta áspera condición de los operarios. La taylorización del trabajo, mal llamada 'racionalización' del trabajo, ha provocado que los trabajadores no necesiten de sus capacidades de atención, inteligencia y creatividad para ejecutar su esfuerzo. Estas doctrinas, ya universalmente extendidas en la época de Weil, siempre fueron pensadas para trabajar más y más rápido, para producir más, en ningún caso para trabajar mejor. Una y otra vez vuelve a encontrar la pensadora una preocupación moderna más por el producto que por el trabajador que produce. Las propuestas de Taylor no han hecho sino sacrificar al obrero en pos de una producción exacerbada tendiente a su vez a un consumismo que se exalta exponencialmente. Todo esto ha derivado en una apremiante pérdida de calificación y oficio en el trabajo del obrero y en el crimen de extinguir la atención intelectual del trabajo manual. Varios años después de su experiencia en la fábrica, en 1942, mantendrá su preocupación sobre este punto:

Pero el peor atentado, el que quizás debería ser equiparado al crimen contra el Espíritu, que no tiene perdón, si no fuera cometido probablemente por inconscientes, es el atentado contra la atención de los trabajadores. Mata en el alma la facultad que constituye en ella la raíz misma de toda vocación sobrenatural. La baja especie de atención exigida por el trabajo taylorizado no es compatible con ninguna otra, porque vacía el alma de todo lo que no sea la preocupación por la rapidez. Este tipo de trabajo no puede ser transfigurado, hay que suprimirlo (Weil, 1951a: 225).

Weil ve aquí una doble alienación: la de los obreros, que ya hemos mencionado, pero también la de los técnicos que no tienen contacto alguno con la materia y el esfuerzo físico que implica trabajar con ella, lo que los reduce a una sabiduría puramente formal sin contacto con la gravedad de la materia. Nuevamente Weil lamenta la separación entre trabajo manual e intelectual que deja a algunos con el contacto vivo con la realidad material y el orden del mundo, pero se les niega la posibilidad de comprenderlo. En el otro lado encontramos a aquellos a quienes se les ha entregado el saber técnico y científico, pero se les ha negado, y ellos lo han aceptado así, el contacto de la materia con su cuerpo, lo que les obliga a ver la realidad desde la distancia de unos conceptos que terminan siendo una película deformadora de lo que es efectivamente el cansancio físico después de 10 ó 12 horas de trabajo. Tanto en uno y otro caso se embota la inteligencia (Weil, 2007: 165). 
Weil está sosteniendo nada menos que una verdadera crítica social debería tener el trabajo físico en el centro de sus especulaciones. La verdadera revolución, la auténtica liberación del trabajador sólo se logrará en una reformulación del trabajo manual. El trabajo manual debe involucrar en sí mismo un grado importante de trabajo intelectual, en la medida en que se realiza más libremente cuando se está consciente de su objetivo, intenciones y de la ciencia y sabiduría que le da vida. Weil considera que la única salida a cualquier tipo de alienación es poder unir nuevamente el trabajo manual y el trabajo intelectual. La filósofa considera que la libertad del hombre está en juego en el hecho de si podemos o no realizar esta unión. Por un lado, devolverle al hombre el pensamiento en toda su amplitud aplicado a su trabajo físico y, por otro, devolverle el trabajo físico en el cual pueda efectivamente tener acceso al orden del mundo desde un contacto real (no ya sólo desde unas ideas) entre el cuerpo y las leyes de la naturaleza. Si se pudiese realizar esta conjunción, no sólo habríamos realizado una ruptura histórica positiva para mejorar las condiciones de trabajo, incluyendo la alegría y libertad en el laborar, sino que habremos hecho crecer y aumentar la libertad misma del hombre en la integridad de su vida. Weil parece indicar que la apropiación del trabajo es el centro desde el cual debe empezar la humanización del hombre. Si esto no está solucionado, será de menor importancia lo que podamos progresar en otros ámbitos de la vida humana y social.

Si los análisis precedentes son correctos, la civilización más plenamente humana sería aquella que tendría como centro el trabajo manual, aquella donde el trabajo manual constituiría el valor supremo [...] No por su relación con lo que produce, el trabajo manual debe convertirse en el valor más alto, sino por su relación con el hombre que lo ejecuta; no debe ser objeto de honores y recompensas, sino constituir para cada ser humano aquello que necesita esencialmente para que su vida tenga por sí misma sentido y valor ante sus propios ojos. Aún en nuestros días, las actividades que se llaman desinteresadas -el deporte, el arte, el pensamiento- no llegan quizá a dar el equivalente de lo que se experimenta luchando directamente con el mundo mediante un trabajo no mecánico (Weil, 1955: 97).

La libertad del hombre frente a otros hombres y frente a la naturaleza, sólo se logrará una vez que hayamos quitado toda opresión en torno al trabajo. Sólo un trabajo libre puede hacer al hombre libre. Esto no es para Weil una reducción del hombre a un puro activismo, a una caricatura de homo faber, porque para ella el trabajo incluye no sólo los aspectos productivos sino también los científicos, culturales, filosóficos y religiosos. La nobleza del hombre, su nobleza racional, emotiva, corporal, so- 
cial y espiritual se desarrollan plenamente en el trabajo libre. No es que las otras dimensiones no existan: la familia, amigos, la experiencia filosófica y religiosa. Lo que dice más bien es que estas otras dimensiones no podrían pensarse como sanamente realizadas si el trabajo no hubiese sido primeramente redimido.

Así de alta es la dignidad que Weil ve en el trabajo, lo que la lleva a criticar en Marx la doctrina de que en la futura sociedad sin clases el hombre estaría liberado totalmente del trabajo, habiendo llegado a una sociedad tan industrializada que ya no necesitaría (o necesitaría muy poco) el esfuerzo que hoy llamamos trabajo (Sparling, 2012: 106; Bea, 2010: 187 ss.). En Weil esto es un error, en primer lugar, porque considera poco realista que se elimine el trabajo incluso en una sociedad hiperindustrializada, ya que tal industrialización debe ser dirigida y controlada, implicando también trabajo. En segundo lugar, porque el problema para el hombre no es el trabajo, sino su dificultad para poder identificarse con él, de poder ver desplegado en él las potencias más altas de su humanidad. Para la filósofa, en síntesis, no sólo no se podría, sino que, sobre todo, no se debería sustraer el trabajo de la vida humana si esta quisiese seguir mereciendo este nombre: "Hay en el trabajo una grandeza cuyo equivalente no se puede encontrar ni siquiera en las formas superiores de la vida ociosa" (Weil, 2014: 324), entendiendo por vida ociosa la parte de la vida sustraída al trabajo directamente productivo.

La clase trabajadora ha sido expoliada del producto de su trabajo, pero también del uso de la palabra y de la alta cultura que la tradición europea ha podido atesorar. La pensadora francesa se lamenta del hecho de cómo se desperdicia tanta experiencia que el trabajador tiene en su trato con la materia al no entregarle las herramientas intelectuales para aplicar su ingenio a esa experiencia y enriquecer su vida. Bastaría acercar un poco los tesoros de esa cultura para que el trabajador aprovechara su entendimiento para apropiarse de esa herencia y llevar su pensamiento a un nivel que tal vez ni siquiera imaginamos. Ese cansancio que es la forma en que la belleza y orden del mundo se introduce en la carne del trabajador. Ese cansancio que es realidad sin distorsiones no se pone nunca en contacto con el pensamiento. Esta es la tragedia que nadie quiere reconocer como tal. Nadie, sostiene Weil, considera como especialmente inhumano el trato que se le da a un imputado de la clase trabajadora, por ejemplo, en el interior de los tribunales. Pareciera que todo estuviera organizado para que el acusado no entendiera nada de lo que ve ni de lo que escucha de esas ceremonias llenas de un lenguaje cifrado y de gestos teatrales. No se ve como especialmente penosa la incapacidad de este hombre de dominar el lenguaje para poderse expresar mínimamente ante personas que seguramente considerará superiores. Todo pareciera señalar 
que los que acusan están en una esfera superior de pensamiento y humanidad, y el acusado se redujera a una sub-humanidad nunca integrable a la verdadera sociedad. No se ve la maquinaria cruel que tras esta escena está funcionando.

Por el contrario, Weil ve la plenitud de humanización y libertad en el trabajo de un grupo de albañiles que piensa, dialoga, planifica y decide frente a un problema que se les presenta en la construcción de un barco o de una casa. La hermosura de esta escena es que hay una sana y próspera conjunción de acción y pensamiento, de sociabilidad y aporte individual, de comprensión de los medios, pero también de los fines últimos de lo que se está haciendo; de conocimiento de la materia, pero también de aplicación de los conocimientos generales que cada uno puede poseer. Hay una comunión de esfuerzo físico, pero también decisiones que son tomadas a partir del objeto y sentido del trabajo que es conocido y consentido por todos los obreros que participan.

Un equipo de trabajadores en cadena vigilados por un capataz es un triste espectáculo; en cambio es hermoso ver un puñado de albañiles, detenidos por una dificultad, reflexionar cada uno por su lado, indicar diversos medios de acción, y aplicar unánimemente el método concebido por uno de ellos, el cual puede indiferentemente tener o no autoridad oficial sobre los demás. En tales momentos aparece casi pura la imagen de una colectividad libre (Weil, 1955: 95).

La unión del marinero y su barco es la unión de la voluntad humana y la materia hasta el punto en que el trabajador se siente dominando la materia y generando desde ella algo nuevo, una verdadera producción con el sello de su corazón y de su historia. Sólo por medio de esta actividad el trabajador no considerará que su trabajo y cansancio son vanos. Él entrega los fines, los tiempos, el carácter, la impronta de su producto. En este tipo de condiciones el trabajo puede entregar felicidad, arraigo y posibilidad de auténtica fraternidad entre los trabajadores. "El artesano que produce sus propias herramientas, su propia materia prima, es rey en su trabajo" (Weil, 2007: 64). Por ello no puede ver sino crueldad en los obstáculos que impone el taylorismo al despliegue de las facultades del trabajador. Por ejemplo, en la intromisión de los técnicos en relación a los tiempos, ritmos y cadencias que el trabajador debe emplear en la realización de su trabajo. Weil lo caracteriza como una intromisión en la intimidad, casi un atropello al pudor debido a una persona. Rescata un comentario de un trabajador que reclamaba por el abuso de los ingenieros a la hora de cronometrar hasta el infinito los objetivos y etapas de su labor, que consideraba como parte del 'secreto profesional' del obrero o, 
al menos, como un espacio de intimidad en el cual sólo tiene fueros el propio individuo trabajador: "El conocimiento de los tiempos de trabajo es para nosotros exactamente lo equivalente de lo que para ellos (los patronos) es el secreto industrial y comercial" (Weil, 1951a: 194).

Con toda la fuerza de su análisis, Weil, finalmente en esta primera etapa, no pareciera querer plantear nada como una especie de solución a la condición obrera. Su noción de poder, heredada de Alain (Émile Chartier), pareciera impedirle el intento de proponer un nuevo orden en la medida que toda organización del poder termina cayendo finalmente en los mismos vicios del poder antiguo que quiso reemplazar. El poder quiere conservarse y, en lo posible, aumentar:

Siempre que los oprimidos quisieron constituir agrupaciones capaces de ejercer una influencia real, esas agrupaciones, ya se llamen partidos o sindicatos, han reproducido integralmente en su seno las taras del régimen que pretendían reformar o abatir, es decir la organización burocrática, la inversión de las relaciones entre medios y fines, el desprecio por el individuo, la separación entre el pensamiento y la acción, el carácter mecánico del pensamiento mismo, la utilización del embrutecimiento y la mentira como medios de propaganda, etcétera (Weil, 1955: 111).

En esta primera estación de su pensamiento, Weil no puede pensar sino que del poder no surge otra cosa más que poder. En esta misma línea no ve más salida que una especie de guerra de guerrillas entre el individuo y el poder anulador de la individualidad y la inteligencia. Por ello plantea sus conclusiones más bien en términos de anhelo, de deseo para que estos oasis de libertad en y gracias al trabajo vayan expandiéndose poco a poco:

Nada, sino esforzarse por dar un poco de juego a los engranajes de la máquina que nos tritura; aprovechar todas las ocasiones para despertar un poco el pensamiento allí donde es posible hacerlo; favorecer todo lo que en el terreno de la política, de la economía o de la técnica, puede dejar cierta libertad de movimiento al individuo dentro de los lazos con que lo rodea la organización social. Ciertamente es algo, pero con esto no se va muy lejos (Weil, 1955: 112).

Su desconfianza en torno al poder la lleva a pensar que la comunidad de los trabajadores no llegará por una reunión en torno a ideologías, ni en torno a la religión, ni siquiera en torno a un sufrimiento en común. Este sentimiento afectuoso entre hombres que se sienten parte de un mismo proyecto es el germen del sentimiento de poder y del 'nosotros' que genera todas las guerras. En definitiva, la transformación de un gru- 
po en masa poderosa que ya no puede desear otra cosa sino el conservar y aumentar el poder. Un colectivismo es siempre una fuerza ciega dominada por la gravedad que no tiene ningún horizonte que contemple la justicia. Y si hace la justicia es sólo por casualidad, pues su preocupación es el poder. Es la bestia del Apocalipsis, es el 'gran animal' de La República de Platón. Este pensamiento se mantiene intacto en toda la obra de Weil: "El orden social, aunque necesario, es esencialmente malo, cualquiera que sea" (1955: 136). El verdadero socialismo para ella está bien alejado de lo que estaba sucediendo en Rusia, ya que el colectivismo es la antípoda de la liberación que desea el socialismo. En un verdadero socialismo es la sociedad quien está subordinada al individuo, no viceversa. No está demás decir esto a favor de la veracidad y valentía de Weil, sobre todo tomando en cuenta su época donde hasta sus propios amigos parecían haber olvidado este postulado base identificando el socialismo sólo con las expropiaciones y las esperanzas en la dialéctica marxista. Es la lucha por la libertad del individuo lo que interesa a la filósofa, no la defensa de una ideología ni la de una forma de estado determinado. A ello se suma la decepción que le generaba cada vez más el carácter poco científico de la doctrina marxista e incluso el carácter 'mágico' y 'religioso' que parecían empapar algunas de sus proyecciones. El término 'religioso' tiene en la Weil agnóstica de esta época un carácter peyorativo, sobre todo al no entender por qué tendría que sobrevenir necesariamente una Jerusalén comunista siguiendo las argumentaciones del marxismo que se acercan a una especie de Providencia dialéctica:

El materialismo revolucionario de Marx consiste en establecer, por una parte que la fuerza sola regula exclusivamente las relaciones sociales, por otra parte que un día los débiles, sin dejar de ser débiles, serán al mismo tiempo los más fuertes. Creía en el milagro sin creer en lo sobrenatural. Desde un punto de vista puramente racionalista, si se cree en el milagro es mejor creer también en Dios (Weil, 1955: 147-148).

El socialismo marxista no es, en definitiva, liberador, pues mantiene la opresión: subordina a los hombres al progreso histórico, entendiendo por esto principalmente el progreso en la producción.

Por ello sostiene que el trabajo traerá paz en la medida en que sea colaborativo, pero no chauvinista ni masificado, es decir, en la colaboración percibo mi valor, pero también percibo el valor del otro y nuestra igualdad como individuos. En el fruto del trabajo se percibe la dignidad del hombre, pero mantenemos nuestra individualidad, no nos identificamos con una masa. Me distingo del otro, pero en ello mismo reconozco su individualidad independiente. $\mathrm{Al}$ reunirnos no como un clan ni una 
mafia, sino al reunirnos a trabajar juntos es como formamos una república, una ciudad de paz y libertad. En una especie de 'ruda amistad' casi sin afecto en que cooperamos teniendo como norte nuestro rol en un trabajo en conjunto: sobre esa experiencia, sobre esa tierra logra prever una esperanza auténtica. Juntarnos como 'trabajadores explotados' es ya juntarnos para deleitarnos en los placeres retorcidos de un poder que quiere seguir alimentándose a expensas de la justicia. "Sólo los trabajadores forman una república. Y por eso es el trabajo, y no la religión ni el amor, lo que fundamentará y fundamenta la paz" (Weil, 2007: 40).

Sin embargo, todavía se mueve su pensamiento en el intento de dar solamente un poco de 'juego a los engranajes que nos trituran', es decir, dentro del sistema de pensamiento que considera que es el poder lo que domina, donde 'la bestia es la dueña aquí abajo', donde pareciera que "El hombre nace esclavo y la servidumbre es su condición propia" (Weil, 1955: 80). Sólo algo distinto de lo que Weil ve como el funcionamiento natural del poder podría hacer que el poder retroceda, se vacíe a sí mismo para dejar ser al otro y a la justicia. Esto distinto lo encontrará la filósofa en sus primeros acercamientos al cristianismo en lo que ella llamará el conocimiento de lo sobrenatural.

\section{EL TRABAJO PARA EL OBRERO CRISTIANO}

Después de la experiencia de trabajo en la fábrica, marcada por el agotamiento, sus fuertes dolores de cabeza y, según sus palabras, 'por la marca de la esclavitud', Simone Weil viaja con sus padres a Asís en Italia y a Solesmes en Portugal (entre los años 1937 y 1938). Es en estos lugares donde nuestra filósofa experimentará sus primeros encuentros con la tradición cristiana. Es en este punto donde comienzan a confluir sus perspectivas anteriores con todo el conocimiento de lo sobrenatural, tal como ella lo llamará.

La concepción de Weil en torno a la fuerza y el poder ya se encuentra en los albores de su obra filosófica. Sin embargo, adquiere una nueva significación luego de su acercamiento al cristianismo. En efecto, la fuerza, el poder o la gravedad (Le pesanteur), como la llamará más extendidamente, es un efecto querido en el mismo acto creador de Dios. Dios en la creación no ha querido conservar para sí todo el poder y ha querido dotar a sus criaturas de un grado de poder para que tuviesen existencia individual y autónoma. Dios es más sin la creación que con la creación. Si Dios no abandonara algo de su poder, Él lo sería todo, Él lo llenaría todo sin dejar ser a las criaturas. Al igual que el sol, que, si estuviese encima de la tierra, no la dejaría ser autónoma, debe retirarse para entregar sus beneficios a la tierra sin destruirla, otorgándole sus poderes para que 
este planeta pueda existir y fructificar como individuo. De igual manera, sostiene Weil, Dios acepta una merma en su poder para que las criaturas puedan tener existencia. Dios se ha vaciado de poder para que la naturaleza pueda tener su propio poder y singularidad. A esto lo ha llamado descreación (décréation). En la ausencia-retirada de Dios es posible verificar su presencia en el mundo. Dios está presente en el mundo por medio de su ausencia (Weil, 1991: 182; 1966: 98). Dios se ha descentrado y ha puesto su atención en algo que no existía y lo ha hecho ser. Por un amor misericordioso ha fijado sus ojos en seres que no eran nada y ha renunciado a tener todo el poder para que pudiesen tener una participación en el ser. Sólo por esta retirada de Dios (o fuerza deífuga) puede la naturaleza tener sus leyes propias, su orden, su belleza, su gravedad (Weil, 1966: 98).

Este sacrificio de Dios desde la fundación del Universo (Estelrich, 2007: 785-786) ha quedado para siempre como la imagen que el hombre puede replicar para hacer entrar lo sobrenatural al mundo. Efectivamente, al retirarse del mundo, Dios lo ha dejado existir, pero lo ha dejado sometido a las leyes naturales, a la gravedad, sin las cuales no tendría sustancia alguna. Y de la gravedad (en esto Weil mantiene su pensamiento inicial) sólo surge gravedad, de la fuerza y el poder sólo más fuerza y poder. Así dejaría a toda la naturaleza (incluido el hombre) sometida a las simples leyes de conservación y expansión. "Dios ha confiado todos los fenómenos sin excepción a la mecánica del mundo" (Weil, 1991: 176). Pero con esto no se ayuda a co-instituir ningún Reino de Dios. La única forma de que el hombre pueda abrir una brecha a la gravedad, dejar un espacio para la Gracia sobrenatural, es que replique, dentro de sus posibilidades, el acto creador de Dios y contraiga su fuerza para dejar ser al otro y a la belleza del mundo. Esto significa que el hombre debe vivir su propia descreación. De otro modo estaría tan lleno de sí, tan ahíto de su propia sustancia, que no podría dejar espacio en su humanidad para que adquiriera consistencia el ser y el sufrimiento del prójimo, la belleza del mundo y el mismo Dios (Weil, 1991: 93).

Su experiencia cristiana más que cambiar su visión anterior en torno al poder y el trabajo lo que hace es expandirla y suplementarla con su peculiar visión de la creación y de la espera de lo sobrenatural (Weil, 1950). El encierro en el cual se encontraba, al desconfiar de toda organización que quisiese ayudar a liberar al hombre porque siempre recaía en los vicios del poder, encuentra una salida en el ingreso del espíritu de Dios en el mundo a través de la descreación. Ha encontrado otra fuerza que no es la sola fuerza conservadora y expansiva de la gravedad, en esta fuerza de la Gracia encontrará Weil la aliada definitiva para la liberación del trabajo humano. 
Desde estas nuevas premisas, Weil va a encontrar la solución del anhelo de sus primeros escritos: la conjunción del trabajo manual e intelectual. En efecto, cuando se refiera al tema del trabajo en esta nueva etapa siempre aludirá a los frutos del cansancio físico para una real contemplación. Con todo lo inconfortable que tiene el cansancio y el agotamiento de los miembros después de una jornada de trabajo, conserva todavía una virtud. El que tiene el cuerpo deshecho por la gravedad de la materia tiene un material de mejor calidad para aplicar sobre él la contemplación intelectual. La gravedad y su revés, la belleza del mundo producto de la obediencia de la materia a las leyes naturales, son experimentadas de una manera muchísimo más real por alguien que conoce esas leyes que abaten su propio cuerpo, que quien sólo las conoce desde la distancia: "Lleva en su carne como una espina la realidad del universo" (Weil, 1966: 116). A diferencia del intelectual, eximio generador de ideologías, quien tiene más a mano la tentación de aplicar una placa de imaginación para edulcorar o adecuar la realidad a sus necesidades, un obrero cansado después de estar sometido a la materia tiene menos espacio para traicionar el orden del mundo que lleva adherido a su carne.

Este es el inmenso privilegio que Dios ha reservado a sus pobres. Pero casi ninguno lo sabe. No se les dice. El exceso de fatiga, la preocupación agobiante por el dinero y la falta de verdadera cultura, les impide darse cuenta de ello. Bastaría un pequeño cambio en su condición para abrirles el acceso a un tesoro (Weil, 1966: 116-117).

Para Weil existe una especie de imaginación demoníaca. La imaginación, generalmente ensalzada, está especialmente inclinada a prostituirse ante los intereses bajos del hombre y a su deseo de colmar vacíos. La soledad, el fracaso, la falta de amor propio, la humillación, pueden compensarse con el alimento siempre dispuesto de la imaginación colmadora de vacíos. En vez de reconocer este vacío, se lo cubre y anestesia para no generar mayor frustración. Weil cree que al trabajo físico le es mucho más difícil realizar esta distorsión de la imaginación. El cansancio tiene demasiado fresca la imagen de las leyes de la naturaleza como para intentar siquiera suavizarlas. Esta obediencia, esta honestidad, este reconocimiento de la realidad es el comienzo de una auténtica espera de la Gracia. Quien está demasiado lleno de ideas y argumentos surgidos de la imaginación difícilmente podrá sentir deseos de lo sobrenatural, difícilmente estará atento a la novedad de la Gracia. Quien está satisfecho de los dulces de la imaginación difícilmente llegará a comprender su necesidad del pan sobrenatural. "El hombre debe realizar el acto de encarnarse, pues está desencarnado por la imaginación” (Weil, 1991: 55 y 110). 
Une ya con toda claridad Weil el trabajo físico a toda posibilidad de contemplación intelectual: desde la contemplación científica a la religiosa. Recuérdese, por ejemplo, sus alusiones a una técnica que no ha sido hecha para los operadores efectivos de las máquinas y su recomendación para inventar una técnica con otro sentido. Piénsese en los ejemplos que entrega de una ciencia basada en los privilegios de clase y cómo esto podría perfectamente cambiar. Sobre todo, es muestra clara de su pensamiento sus ideas acerca del trabajo campesino y el cristianismo. Ella ve que el mismo trabajo campesino puede ser un medio único para enseñar a los hombres la revelación y darles un pleno sentido a sus vidas.

La obediencia a la gravedad que imprime el cansancio en nuestro cuerpo es un medio que el trabajador tiene para hacerse materia como Dios mismo se hace materia en la eucaristía (Weil, 1991: 275). Dios en Cristo obedece el orden del mundo, las leyes de la gravedad, hasta el sacrificio en cruz, hasta hacerse pan y vino en la eucaristía. De igual manera el trabajador consume toda su energía en su obediencia al orden del mundo para transformarla en pan y vino para otros y para sus hijos. "Trabajar cuando se está agotado es volverse sumiso al tiempo, como la materia" (Weil, 1991: 275). Los miembros desechos del trabajador son semejantes, sostiene Weil, a una consagración. Sería ridículo, sin embargo, ver en estas afirmaciones una especie de resignación fatalista ante la situación obrera. La trayectoria de lucha por la justicia de Weil sería suficiente para rechazar una interpretación como esta. Si no se aprovecha este agotamiento y sin intervención de la Gracia, este cansancio puede continuar humillando y empequeñeciendo al hombre.

\section{EL TRABAJO: VISIÓN AGNÓSTICA Y CRISTIANISMO}

Con todos estos antecedentes intentaremos dilucidar ahora cómo el desarrollo de la doctrina de Weil en torno al trabajo va manifestando al mismo tiempo una especial visión antropológica y metafísica. Comenzaremos señalando que en la cosmovisión de Weil hay una dualidad muy marcada, aunque ella pida que deba pensarse siempre como una unidad. Hablamos de la dualidad Gravedad-Gracia (Perrin \& Thibon, 2015: 247). Por una parte, el orden del mundo con sus leyes implacables de fuerza que no podemos sino obedecer en cuanto son la condición para que este universo tenga algún grado de ser y autonomía. Es el abandono-ausencia de Dios que ha permitido que brote la existencia del mundo. Por otro lado, el reino sobrenatural que adviene sólo en cuanto obedezcamos la gravedad sin mentiras ni distorsiones en una espera atenta y vacía de contenidos imaginarios. Aunque trate de matizarlo, este dualismo permanece en su filosofía de madurez y la lleva a tener una visión negativa 
de la fuerza, el poder, la gravedad: en síntesis, de buena parte de su concepción de la creación. Pareciera que del poder no surgiera sino maldad. Esta visión negativa de la creación que le exige imperiosamente una descreación pensamos que viene heredada no sólo de Alain —su maestro de filosofía en la enseñanza secundaria- sino de su admiración por las doctrinas cátaras, maniqueas y platónicas que siempre profesó. La filósofa se centra en las acciones del Dios cristiano que manifiestan una 'huida del poder': su humillación, su tortura, su muerte en cruz (Plant, 1996: 81), pero es verdad que en su encarnación Dios también hizo uso de su poder y no se mostró como un Dios impotente, pese a que quiso nacer y vivir en una condición humilde y sencilla. Weil frente a esto señala que los milagros y los prodigios son el aspecto 'humano' y casi bajo de su misión (Weil, 1991: 154). Para Weil las verdaderas religiones son aquellas donde lo divino se muestra en su grado más alto de debilidad e indefensión (sinónimo en ella de descreación, es decir, de amor y pureza). Como el más excelso ejemplo de este paradigma sitúa al cristianismo (Estelrich, 2007: 786). Sin embargo, creemos que una visión de este tipo reduce a Cristo a un ser aplastado por la gravedad, en definitiva, lo reduce a ser un fracasado, que no pudo oponer nada a las frías y ciegas leyes de la naturaleza corpórea y social. Más que un Dios débil lo que vemos en Cristo es un Dios hecho hombre que quiere siempre respetar el libre consentimiento de todos. Sus milagros son intentos de recomponer la naturaleza trizada del hombre y mostrar la conveniencia de su amistad, pero en ningún caso imponerse arbitrariamente a la voluntad de otros como pareciera entender Weil el uso del poder en todos los casos (en el caso de Cristo entender sus milagros como un recurso para acarrearse prestigio social, poder, estatus ante la colectividad). Como hombre, Cristo utiliza sus facultades lealmente para recomponer con los hombres el Reino de Dios (Chenavier, 2009: 59).

Se reafirma esta visión degradada que Weil tiene de la creación en el hecho de que sea necesario descrearla para que puedan surgir los buenos frutos de la Gracia. "Dios mío, concédeme que me convierta en nada. A medida que me voy convirtiendo en nada, Dios se ama a través mío" (Weil, 1991: 84). La naturaleza tendría que desaparecer o anularse para que pudiese advenir el Reino de Dios (Bea, 1992: 189). Sin embargo, es fácil reconocer bien a lo largo de toda la tradición cristiana que la gracia no pretende destruir la naturaleza sino perfeccionarla (Tomás de Aquino, Suma de Teología, I, q.1, a8, ad2) y que hablar tan absolutamente mal de la creación es de alguna manera hablar mal del mismo Creador (Tomás de Aquino, Suma contra Gentiles, 3, q.69), es considerar a Dios un creador de pésimo gusto. La naturaleza en el cristianismo está dañada por el pecado original, pero no está completamente corrupta (Estelrich, 2007: 789). El 
trabajo bueno de la naturaleza más el trabajo bueno del hombre son necesarios para que la Gracia pueda actuar. Sin esta colaboración sería imposible co-instituir con Cristo el Reino recompuesto.

Weil, en cambio, considera el trabajo como una manera de descrearse en cuanto nos hace obedientes al orden del mundo y destruye en nosotros esa falsa divinidad que llamamos yo. Es verdad que nos hace conscientes de esa gravedad al quedar esta clavada en nuestro cuerpo como una espina, pero esa misma conciencia nos permitiría ver que ese yo no es sino otro elemento sometido como el resto de la naturaleza. Esa conciencia de nulidad nos haría dirigir la mirada hacia lo alto. Weil ve el trabajo como una posibilidad de despersonalización (Fuster, 2013: 147; Perrin \& Thibon, 2015: 143), de renuncia al falso poder que no eleva definitivamente (el poder natural). Creemos que Weil no puede entender el trabajo como la composición entre el trabajo del hombre y el trabajo de Dios. Weil tiende a ver el trabajo como la retirada del trabajador para que quien finalmente trabaje sea la Gracia sobrenatural. Mi trabajo sólo consistirá en desaparecer en individualidad para que lo sobrenatural pueda acceder a modificar la naturaleza. El trabajo sano del hombre no puede aportarle nada a Dios. Dios no se enriquece en nada con el trabajo bueno del hombre y no podría componer con él (con su ayuda, con su ingenio) una ciudad cristiana (Plant, 1996: 100). En el sistema de Weil el hombre sólo puede aportarle a Dios su descreación:

Sólo Dios es capaz de amar a Dios. Lo único que nosotros podemos hacer es renunciar a nuestros sentimientos propios para dejar paso a ese amor en nuestra alma. Esto significa negarse a sí mismo. Sólo para este consentimiento hemos sido creados (Weil, 1966: 88-89).

En muchos textos, sin embargo, pareciera que el trabajador - al menos el proletario de su época- ni siquiera alcanzaría a tener este mínimo de poder para descrearse. Su situación sería la de una conciencia despojada de todo prestigio y estatus y, por ello, la de alguien completamente aplastado por la gravedad. La descripción que ella hace de ellos es prácticamente la descripción de unos esclavos que no pudiesen levantarse ni un milímetro por sus solas fuerzas. Creemos que detrás de esta visión se esconde cierto paternalismo, como si los obreros ni siquiera pudiesen hacerse cargo de su propio sufrimiento. Como si ni siquiera pudiesen aprender de sus propias desdichas. Nadie negaría el compromiso de Weil con los que más sufrían ni nadie dudaría de la autenticidad de esa caridad que siempre demostró hacia ellos con hechos y a riesgo de su propia comodidad, pero es verdad que podría haber tenido una valoración mayor de la individualidad obrera siendo ella conocedora de primera fuente 
del esfuerzo de los obreros para sindicalizarse, reunirse a debatir, organizarse y vivir dignamente. Nos parece lamentable que Weil, pudiendo apreciar esto en contacto directo con ellos - su experiencia en la fábrica y en la gran huelga metalúrgica de Francia de 1936-, mantuviera esta visión tan pobre y escuálida de la situación obrera, incluso reconociendo todas las injusticias que se cometían contra los trabajadores. La descripción de su condición de trabajadora en la fábrica es aplastante:

¿Cómo yo, la esclava, puedo subir a este autobús y usarlo por mis cuatro perras con el mismo derecho que cualquier otro? ¡Qué favor extraordinario! Si me hicieran bajar brutalmente diciéndome que estos medios de locomoción tan cómodos no son para mí, que debo ir a pie, yo creo que me parecería lo más natural. La esclavitud me ha hecho perder completamente el sentimiento de tener derechos. Me parece un favor tener momentos en que no tenga que soportar nada de la brutalidad humana. Estos momentos son como sonrisas del cielo, un don del azar. Esperemos que conserve este talante tan razonable (Weil, 1951a: 82).

Son sintomáticas las ocasiones en las que Weil misma se sorprende de que los trabajadores no compartan una visión tan deplorable de su propia condición (Weil, 1951a: 25).

Se nos podrá contra argumentar que Weil no tiene una visión degradada de la creación por las muchas páginas que dedica a la belleza del mundo. Sin embargo, ella entiende por belleza del mundo la obediencia a las frías leyes de la naturaleza. El orden del mundo es bello porque es totalmente obediente y quien acepta este orden del mundo tiene él también la posibilidad de observar en sí y en el universo la belleza de la sabiduría divina. Sin embargo, esta belleza es bien amarga si este orden del mundo se me presenta como agotamiento mortal de mi cuerpo o como enfermedad. Pálido premio sería para alguien que está sufriendo los rigores metálicos de las leyes naturales argüirle que tiene una oportunidad única de contemplar la sabiduría de Dios. Este beneficio estético intelectual es poca cosa al lado del dolor auténtico de un hombre.

Todo esto concluye en Weil en un debilitamiento del cristianismo como acontecimiento histórico. En efecto, la intervención de Dios en la historia, por mucho que sea la intervención en el Hijo hecho hombre, es la situación de alguien que asume las fuerzas del cuerpo humano para actuar en el mundo. Jesús mismo actúa e influye con sus palabras y milagros. Tiene un poder que utiliza para ayudar al hombre, pero pareciera que estas narraciones no gustaran tanto a Weil. Para ella el verdadero cristianismo es la desdicha de Dios, su crucifixión, su debilidad, su muerte en cruz. No pareciera agradarle la 'mundaneidad' e 'historicidad' de 
Cristo, el uso de sus facultades humanas en el trato con los hombres. Por ello se escapa hacia lo eterno con una especie de cristianismo de las ideas que podría ser compartido por otros pueblos, religiones y culturas muy alejadas en la historia, pero unidas entre sí por la intuición intelectual del verdadero Dios que se hace débil para salvar al hombre. "La historia de Prometeo es como la refracción en la eternidad de la Pasión de Cristo. Prometeo es el cordero degollado desde la fundación del mundo" (Weil, 1951b: 94). "El pasado y el futuro son simétricos. La cronología no puede tener un papel determinante en una relación entre Dios y el hombre, relación en la que uno de los términos es eterno" (Weil, 1951c: 18). "Hay que buscar inspiración en las verdades eternamente inscritas en la naturaleza de las cosas" (Weil, 1949: 145). Esto hace del cristianismo una sabiduría intemporal cuya encarnación en la historia del hombre tiene nula importancia, es decir, una nueva modulación del gnosticismo. Creemos que en Weil no hay una comprensión cabal del carácter histórico del cristianismo (Plant, 1996: 50; Chenavier, 2009: 52; Bea, 1992: 174).

Por todo esto podemos concluir que, paradójicamente, nos parecen más asimilables a una doctrina cristiana del trabajo sus escritos de su época agnóstica que sus propuestas en relación a este tema posteriores a su encuentro con el cristianismo. La razón radica, a nuestro modo de ver, en que durante sus últimos años se acerca a un cristianismo con claras trazas de dualismo y espiritualismo que tiñe todas sus apreciaciones, incluso las éticas y las políticas. Antes de estos pensamientos religiosos, en cambio, es sólo el realismo lo que la hace juzgar. Ninguna influencia ideológica logra distorsionar su mirada hacia la condición de los trabajadores, por ello creemos que es esta doctrina primera la que, extrañamente, más podría aportar a una visión cristiana del trabajo, más que sus posturas cristiano-maniqueas de las cuales nunca se desligó totalmente en su posterior 'cristianización' (Perrin \& Thibon, 2015: 248).

\section{REFLEXIONES FINALES}

Como hemos visto, la doctrina sobre el trabajo es un pilar fundamental en este pensamiento y es oportunidad para evaluar con claridad la visión general -metafísica y antropológica- que la fundamenta. En este sentido hemos podido observar - y con ello podríamos ya dar respuesta a nuestra pregunta inicial y confirmar nuestra hipótesis- cómo la noción del trabajo de la Weil cristiana - la Weil de sus últimos escritos y de sus últimos años de labor intelectual antes de su muerte al servicio de la Francia libre en 1943- es un claro reflejo de una concepción espiritualista y gnóstica de la realidad. En su primera etapa de pensamiento, pese a la gran influencia de Marx, logra tener la autonomía de pensamiento para 
criticarlo en puntos esenciales teniendo como referencia la mirada atenta a los acontecimientos políticos de Europa. Aunque hay que señalar que ya en este período posee la concepción de fuerza - heredada de Alain y, en cierta medida, de sus estudios del mecanicismo de Descartes, pero sobre todo de su inmensa admiración de la cosmovisión griega vista desde los filósofos y los trágicos (Estelrich, 2007: 783-784) - que somete al hombre tanto a través de las leyes naturales como a través de las leyes sociales y que tan poca esperanza la harán abrigar en torno a una época de mayor libertad para la humanidad. Sin embargo, pese a su reconocimiento de este mecanismo muy cercano también del amor fati estoico, no deja de tener cierta cálida, aunque pequeña esperanza en al menos 'dar un poco de juego', 'crear un espacio de movimiento libre' dentro de los engranajes de esa máquina que nos tritura.

En este sentido, podríamos sintetizar lo que creemos es el mayor aporte weiliano a una doctrina del trabajo en los siguientes puntos:

1. El trabajo debe alejarse de una hiper-especialización que anule la capacidad del obrero de generar ideas generales o, mejor dicho, que anule su capacidad de tener una visión general de la realidad. En este sentido sostiene derechamente que el trabajo debe considerarse como una manera de educar permanentemente a las personas. "Este es mi ideal: una sociedad en la que el trabajo fuera el primer medio de educación" (Weil, 2014: 323). Un trabajo donde el obrero no esté constantemente aprendiendo, enriqueciéndose y madurando es, a la larga, un trabajo empobrecedor. La labor diaria es un trato del hombre con la materia, pero también una posibilidad de auto-conocimiento e instancia de expansión de nuestras facultades. Privarle a alguien del trabajo es privarlo de esta posibilidad de crecimiento y de educación (Weil, 1951a: 132-133).

Es necesario que en el trabajo se pongan en juego una serie de facultades para que efectivamente el lugar donde pasamos la mayor parte de nuestra vida pueda implicar necesariamente educación y humanización. Entre las facultades que Weil considera que se desperdician en los trabajadores con la actual división del trabajo se encuentran: la iniciativa, la invención, la investigación, la elección de los procedimientos más eficaces, la responsabilidad, la comprensión de la obra a realizar y de los métodos a emplear, etc. (Bea, 1992: 78). En este mismo sentido argumentaba la pensadora reflexionando sobre su experiencia obrera:

Cuando las órdenes confieren una responsabilidad a quien las ejecuta, exigen por su parte las virtudes de la valentía, de la voluntad, de la conciencia y de la inteligencia que definen el valor humano, implican una cierta confianza mutua entre el jefe y el subordinado, y no comportan más que en escasa medida un poder arbitrario en manos del jefe, la subordinación es 
una cosa bella y honorable. Dicho sea de paso, le hubiera estado reconocida a un jefe que un día hubiera querido asignarme alguna tarea, incluso penosa, sucia, peligrosa y mal retribuida, pero que hubiera implicado cierta confianza en mí; y hubiera obedecido, ese día, de todo corazón. Y estoy segura de que muchos obreros son como yo. Este es un recurso moral que no se utiliza (Weil, 1951a: 134-135).

2. Simone Weil sostiene a lo largo de toda su obra que la separación entre trabajo manual e intelectual es un gran error. Como ya hemos visto, quitarle al trabajador manual la posibilidad de generar una cosmovisión y de utilizar su inventiva, es reducirlo a un instrumento más sometido a voluntades ajenas y desconocidas. Sin embargo, una cultura donde el trabajo intelectual es separado totalmente del contacto con la materia también es una gran pérdida para estos trabajadores. Entendemos que seguramente Weil cae en una defensa excesiva de las riquezas del trabajo manual y también entendemos que no necesariamente un trabajo intelectual llega a estas ilusiones sobre lo real. Sin embargo, estamos de acuerdo con ella en que en el trabajo manual hay una riqueza que no es posible obtener de otro modo si no es en ese tipo de labores y en ese tipo de esfuerzo (Chenavier, 2009: 63). La experiencia provocada en el trabajo directo con la materia podría generar instancias de pensamiento todavía no lo suficientemente aprovechadas. Razón lleva la filósofa cuando sostiene que una persona que ve cómo su esfuerzo y su cuidado más las propiedades de la luz y la tierra van transformando a su viña en vino y a su trigo en pan, en definitiva, le es más fácil comprender, por ejemplo, cómo Cristo pueda transformarse en pan y vino. En este sentido rescatamos la propuesta de Simone Weil de hacer retornar la contemplación y la atención al trabajo manual y de acercar el trabajo manual al intelectual, como una veta de pensamiento todavía poco explorada para la ciencia, la filosofía y la teología (Weil, 1951a: 223).

Ahora bien, hay que reconocer que la situación actual del trabajo dista mucho de posibilitar un retorno tan fácil del trabajo manual. Como bien lo expresa Chenavier:

¿Cómo pensar en nuestras condiciones que son las nuestras desmoronamiento o hundimiento de la sociedad salarial-, tan contrarias a las que deseaba Simone Weil, en una cultura y en una espiritualidad capaces de desarrollar tanto las posibilidades de la existencia corporal como las del pensamiento? ¿Cómo se pueden orientar los movimientos del cuerpo y la actividad del espíritu hacia la más elevada atención si el espesor sensible del mundo se evapora en propiedades numéricas que eliminan cualquier contacto con la materia (lo que se da en las formas de trabajo asistido por ordenador)? (en Bea, 2010: 198). 
Pensamos que, pese a los cambios radicales que se han vivido en los últimos decenios, es posible todavía mantener esta esperanza weiliana de unir trabajo manual e intelectual en la medida en que entendamos esta esperanza, como nos parece que ella la entendió, sobre todo como una posibilidad de encarnación para el hombre. El hombre por medio de su trabajo reconoce y asume la realidad sin distorsiones. El carácter de 'manual' del trabajo creemos que se mantendría si buscáramos un trabajo que respetara la corporalidad humana, en su residencia en un espacio y un tiempo. El respeto por el espacio, intimidad, ritmo, velocidad, pausa, cadencia, creatividad enlazadas juntas por el mismo sentido del trabajo para una mayor adquisición de libertad en la labor diaria, nos parece que es necesario hasta el día de hoy. Es verdad que reducirlo todo a 'manualidad' sería difícil de aplicar tal como camina la economía actualmente, pero si observamos el trasfondo de la propuesta de la filósofa de entender el trabajo como un proceso de encarnación o encarnamiento, nos parece que podría continuar siendo una propuesta muy actual. Sobre todo, en la medida en que observamos al día de hoy labores intelectuales que impiden todavía al hombre conocerse y conocer la realidad en su amplitud, que son a todas luces muy funcionales a la economía, pero fuentes claras de enajenación en la medida en que parecieran transcurrir en una realidad paralela o, al menos, una realidad muy parcelada (Revilla, 2000: 128; Juan Pablo II, 1981: n.24; Chenavier, 2009: 64).

3. Creemos que es acertada la propuesta de la filósofa en relación a que el orgullo del trabajador por su trabajo y su compromiso con él implicaría un mayor orgullo y compromiso con su patria (Juan Pablo II, 1981: n.10; Bea, 1992: 111). Es más, si el trabajo fuera realmente educador para el obrero, si despertara crecientemente sus facultades, si además percibiera que su trabajo coopera en la creación de una sociedad, de una ciudad, de una ciudadanía, si comprendiera que con su trabajo colabora en la composición del Reino de Dios, se sentiría auténticamente en una patria que podría considerar como propia. Esto tendría una serie de repercusiones en su compromiso político y social y, en síntesis, repercusiones en la marcha moral de una sociedad. Si el trabajador no siente que ya coopera en el bien común dentro de su trabajo, difícilmente creerá que puede hacerlo fuera de su trabajo en las instituciones políticas de una sociedad. El desarraigo dentro de la fábrica, dentro del lugar de trabajo, genera desarraigo del país y de los seres humanos que lo habitan (Chenavier, 2009: 35). Por ello concordamos con Weil en que una rehabilitación del trabajador con el sentido último de su esfuerzo diario generaría una rehabilitación cada vez mayor con los otros fines de su vida: "Los obreros sólo se sentirán verdaderamente en casa en su propio país, y miem- 
bros responsables del país, cuando se sientan como en casa en la fábrica donde trabajan" (Weil, 1951a: 209).

En este mismo sentido reclama Weil la urgencia de hacer retornar la belleza en el trabajo. Efectivamente el trabajo no es un juego, implica en ocasiones cansancio, aburrimiento y a veces dolor. Sin embargo, no por ello debería estar ausente en él la poesía propia de todo lo que es verdaderamente grande, y para Weil el trabajo es una de las cosas más grandes. En efecto, el trabajo conlleva la posibilidad del conocimiento sobrenatural del mismo Dios, por ello el trabajo debería ser bello e incluso más bello que la floración primaveral o la rotación de los astros. Es, sin duda, hermosa la formación de glaciares o los bosques de coral, pero es aún más hermosa la construcción de una casa o el diálogo que arman los trabajadores para construir un puente. Esta belleza, esta poesía es la que debe recuperarse para el trabajador o, si ya existe esta belleza, ser capaces de mostrársela: "El pueblo tiene tanta necesidad de poesía como de pan. No de la poesía encerrada en las palabras; esa, por si misma no puede serle de ninguna utilidad. Tiene necesidad de que la propia sustancia cotidiana de su vida sea poesía" (Weil, 1951a: 219). Cuánto arraigo en su patria, cuánto orgullo para el trabajador y su familia, cuánta alegría para el obrero podría provocar la conciencia de que nuestra labor diaria es tan hermosa como una cantata de Bach o como una delicada danza y mucha más hermosa que cualquier expresión de la magnificencia de la naturaleza. Por ello critica la filósofa la rapidez y velocidad que se le imprimen al trabajo al interior de las fábricas, no porque ella tenga un deseo absurdo de lentitud, sino porque es una velocidad impuesta desde afuera que no respeta el ritmo y armonía de toda obra de arte. Weil contrapone este atolondramiento y aceleramiento del trabajo taylorizado con el campesino que siega y que pareciera 'tomarse todo el tiempo del mundo', pero que pese a ello avanza con una rapidez sorprendente. Por ello su crítica a esta uniformidad sin variedad del trabajo de las fábricas en contraposición a la unión sublime de monotonía y variedad de las constelaciones, del canto gregoriano y del trabajo bien hecho:

Una uniformidad que imita los movimientos de los relojes y no la de las constelaciones, una variedad que excluye toda regla y por consiguiente toda previsión, constituye un tiempo inhabitable para el hombre, irrespirable...el espectáculo de los peones en las máquinas es casi siempre el de una precipitación miserable de la que están ausentes toda gracia y toda dignidad. Es natural y propio del hombre pararse cuando ha hecho alguna cosa, aunque sea el espacio de un relámpago, para tomar conciencia de ello, como Dios en el Génesis (Weil, 1951a: 207-213). 
Tomando en serio esto, efectivamente el trabajo humano podría ser fuente de felicidad y de salvación para el hombre. Incluso sus reflexiones nos parecen más amplias que las actuales propuestas de una sociedad del conocimiento que abogan por otorgarle mayor información y valor agregado a los productos del trabajo. Estas doctrinas nos parecen que, si bien recogen los movimientos del mundo del trabajo en los últimos decenios, se han reducido todavía a ver el trabajo sólo como medio de producción económica. Weil era más ambiciosa en este punto y veía en el trabajo el posible centro de la vida espiritual del hombre y de la sociedad entera. En este sentido estamos de acuerdo con Emilia Bea en señalar que:

En esta búsqueda de una civilización auténticamente universal, identificada con una civilización del trabajo, se cifra el último mensaje con que Simone Weil nos continúa interpelando en la actualidad (Bea, 1992: 22).

Queda en pie, entonces, el intento de superar la división que se arrastra desde los filósofos griegos entre el trabajo físico y la contemplación intelectual. La división odiosa entre el trabajo esclavo y el ocio libre de los intelectuales. Queda en pie la propuesta de Weil de generar una nueva civilización cuyo factor de unión, cuya amistad de base, cuyo suelo de fraternidad sea el trabajo colaborativo de hombres libres. Un trabajo que incluye el espacio, tiempo, esfuerzo y contemplación del hombre, toda su corporalidad, toda su racionalidad, en definitiva, todo su ser. Es a través de esta nueva cultura del trabajo donde se encontrará, según Weil, la auténtica paz social.

\section{REFERENCIAS}

-Bea, E. (1992). Simone Weil. La Memoria de los Oprimidos. Madrid: Encuentro. -Bea, E. (2010). Simone Weil. La conciencia del dolor y la belleza. Madrid: Trotta.

-Chenavier, R. (2009). Simone Weil: La atención a lo real (A. del Río, Trad.). Madrid: Fundación E. Mournier.

-Estelrich, T. (2007). Creación y descreación en la filosofía de Simone Weil. Pensamiento, 63(238), 777-795.

-Fuster, A. (2013). Demorarse en el mirar. La imaginación en Simone Weil, Iris Murdoch y Hannah Arendt. Revista Internacional de Filosofia, (60), 141-157.

-Juan Pablo II (1981). Carta encíclica Laborem Exercens.

-Marx, K. (2009). El Capital (P. Scaron, Trad.). México: Siglo XXI.

-Perrin, J. M. \& Thibon, G. (2015). Simone Weil, tal como nosotros la conocimos (A. Álvarez, Trad.). Granada: Nuevo inicio.

-Plant, S. (1996). Simone Weil (M. T. Solana, Trad.). Barcelona: Herder.

-Revilla, C. (2000). Habitar el universo: el tema del trabajo en el pensamiento político de Simone Weil. Convivium, (13), 109-128. 
-Sparling, R. (2012). Theory and Praxis: Simone Weil and Marx on the Dignity of Labor. The Review of Politics, 74(1), 87-107.

-Weil, S. (1949). L'enracinement. París: Gallimard.

-Weil, S. (1950). La connaissance surnaturelle. París: Gallimard.

-Weil, S. (1951a). La condition ouvrière. Montreal: Gallimard.

-Weil, S. (1951b). Intiutions pré chrétiennes. París: La Colombe.

-Weil, S. (1951c). Lettre à un religieux. París: Gallimard.

-Weil, S. (1955). Opresión et liberté. París: Gallimard.

-Weil, S. (1966). Attente de Dieu. París: Fayard.

-Weil, S. (1991). La pesanteur et la Grace. París: Plon.

-Weil, S. (2007). Escritos históricos y políticos. Madrid: Trotta.

-Weil, S. (2014). La condición obrera. Madrid: Trotta.

Sumario: Introducción; 1. Simone Weil y la crítica a la función; 2. El trabajo para el obrero cristiano; 4. El trabajo: visión agnóstica y cristianismo; 5. Reflexiones finales; Referencias. 